\title{
Capacidade antioxidante total de óleos vegetais comestíveis: determinantes químicos e sua relação com a qualidade dos óleos ${ }^{1}$
}

\author{
Total antioxidant capacity of edible vegetable \\ oils: chemical determinants and \\ associations with oil quality
}

Vanessa Naciuk CASTELO-BRANCO ${ }^{2}$

Alexandre Guedes TORRES²

RE S U M O

A capacidade antioxidante total de óleos vegetais comestíveis é determinada por sua composição físico-química e pode estar associada a atributos de qualidade dos óleos, especialmente a sua bioatividade e possivelmente a sua estabilidade oxidativa. Este artigo apresenta os fundamentos dos ensaios de capacidade antioxidante total e avalia criticamente os ensaios aplicáveis na análise de óleos e os pontos críticos nas aplicações dos ensaios para a análise dessas amostras. Discute-se o potencial papel dos componentes químicos dos óleos comestíveis como determinantes da capacidade antioxidante total, assim como a possível relação da capacidade antioxidante com a bioatividade e a estabilidade oxidativa dos óleos. Finalmente, discutem-se evidências de que, caso seja sistematicamente investigado em trabalhos experimentais futuros, o uso de ensaios de capacidade antioxidante total na análise de óleos vegetais pode contribuir para integrar o conhecimento da composição química com a bioatividade e possivelmente com a estabilidade de óleos vegetais específicos. Dessa forma, os ensaios de capacidade antioxidante apresentam potencial para aplicação no controle da qualidade integral de óleos comestíveis.

Termos de indexação: Antioxidantes. Óleos vegetais. Peroxidação de lipídeos. Radicais livres.

A B S T R A C T

The total antioxidant capacity of edible vegetable oils is determined by their physical-chemical composition and might be associated with their quality attributes, especially with bioactivity and possibly with oxidative

\footnotetext{
1 Artigo elaborado a partir da dissertação de V.N. CASTELO-BRANCO, intitulada "Capacidade antioxidante total de óleos vegetais refinados: contribuição ao estudo de seus determinantes". Universidade Federal do Rio Janeiro; 2009.

2 Universidade Federal do Rio de Janeiro, Instituto de Química, Programa de Pós-Graduação em Ciência de Alimentos, Laboratório de Bioquímica Nutricional e de Alimentos. Av. Athos da Silveira Ramos, 149, Centro de Tecnologia, Bloco A, Sala 528A, Cidade Universitária, 21941-909, Rio de Janeiro, RJ, Brasil. Correspondência para/Correspondence to: A.G. TORRES. E-mail: <torres@iq.ufrj.br>.
} 
stability. The current review presents the fundamentals of total antioxidant capacity assays and critically evaluates the assays applicable to the analysis of oils. The role of the chemical components of edible oils as determinants of total antioxidant capacity is discussed, as well as the potential associations between antioxidant capacity and bioactivity or oxidative stability of the selected oils. Finally, we discuss evidences that, if systematically addressed in future experimental work, the application of total antioxidant capacity assays to vegetable oils might contribute to link the knowledge about their chemical composition with their bioactivity, and possibly with the stability of specific vegetable oils. Thus, antioxidant capacity assays can potentially be used for the quality control of edible oils.

Indexing terms: Antioxidants. Plant oils. Lipid peroxidation. Free radicals.

\section{N T R O D U Ç Ã O}

Os antioxidantes naturais de óleos vegetais apresentam potencial efeito na prevenção de doenças crônicas, pois são capazes de proteger sistemas biológicos contra a ação de espécies reativas de oxigênio e nitrogênio, responsáveis por danos oxidativos aos lipídeos, proteínas e ácidos nucleicos ${ }^{1,2}$. Além de apresentarem bioatividade no organismo humano, os antioxidantes naturais protegem os óleos vegetais contra a ação de radicais livres que iniciam e perpetuam a peroxidação lipídica, que consiste na principal forma de degradação dos óleos vegetais e em importante fonte de prejuízos para a indústria de alimentos ${ }^{3}$. Dessa forma, os antioxidantes naturais presentes nos óleos vegetais têm sido foco de interesse científico e tecnológico nas áreas de ciência de alimentos e nutrição, a partir de duas abordagens principais: promoção de maior estabilidade oxidativa dos óleos e bioatividade no organismo humano. A capacidade antioxidante total dos óleos vegetais, possivelmente, sintetiza de forma integrada a ação dos antioxidantes, com potencial benefício para a saúde humana e para a estabilidade de óleos vegetais específicos.

Uma grande variedade de antioxidantes naturais está presente nos óleos vegetais, tais como os tocóis $(\alpha-, \beta$-, $\gamma$ - e $\delta$-tocoferol e tocotrienol), os carotenoides, os compostos fenólicos e os esteróis (Figura 1). Além disso, diversos antioxidantes sintéticos podem ser adicionados aos óleos com a finalidade de protegê-los da oxidação, tais como o Butil-Hidroxi-Anisol (BHA), Butil-Hidroxi-Tolueno (BHT) e Terc-Butil-Hidroquinona (TBHQ) ${ }^{3}$. Atualmente, sugere-se que a atividade dos compostos antioxidantes dependa de
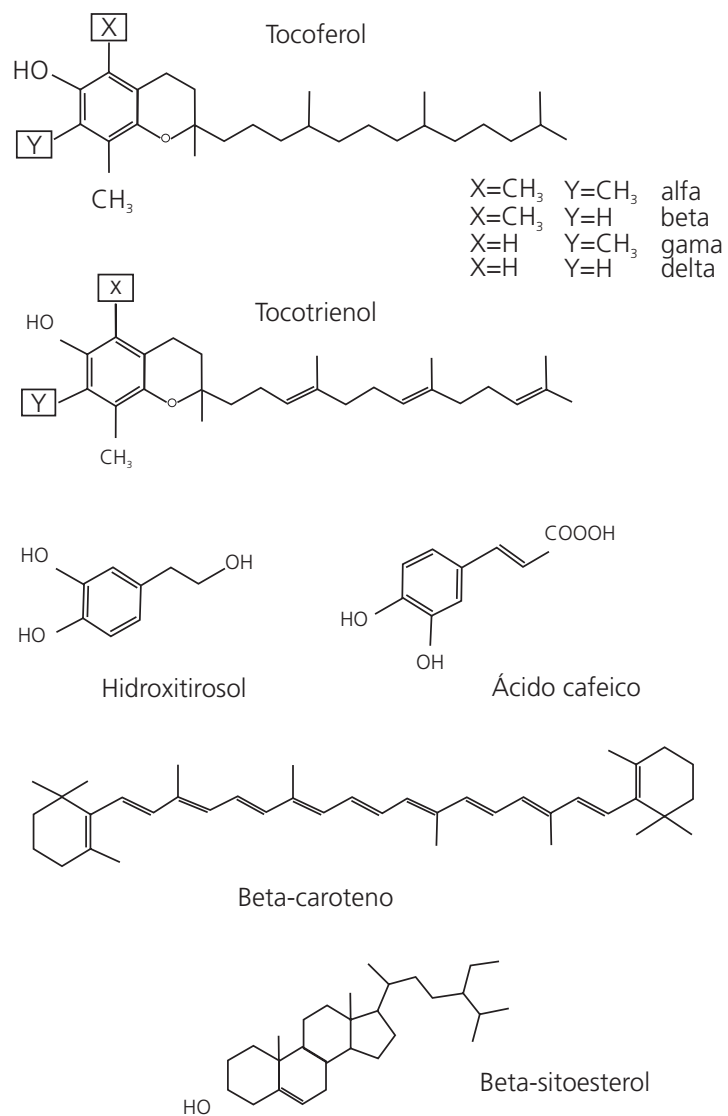

Figura 1. Estruturas químicas dos principais antioxidantes naturais presentes nos óleos vegetais comestíveis: tocoferóis e tocotrienóis; hidroxitirosol; ácido cafeico; $\beta$-caroteno e $\beta$-sitosterol.

diversos fatores físico-químicos, como, por exemplo, interações entre os compostos antioxidantes e destes com outros componentes do meio, como ácidos graxos quimicamente ligados a fosfolipídeos ou triacilgliceróis ${ }^{4}$. Portanto, o estudo de um composto, isoladamente, pode levar a resultados limitados. Por isso, existe um crescente interesse por métodos capazes de avaliar de forma inte- 
grada a ação de compostos antioxidantes presentes nos óleos vegetais. Possivelmente, os ensaios de capacidade antioxidante irão atender a essa demanda ${ }^{5,6}$.

A determinação da capacidade antioxidante em óleos pode ser considerada um desafio analítico, pois a maioria dos métodos foi desenvolvida para a análise de compostos hidrofílicos em amostras aquosas ou hidrofílicas. Os óleos vegetais são hidrofóbicos e não se misturam ao meio aquoso, peculiar aos ensaios de capacidade antioxidante. Consequentemente, a turbidez da amostra prejudica a determinação e os resultados gerados não são reprodutíveis ${ }^{7}$. Dessa forma, são necessárias adaptações nos ensaios de capacidade antioxidante para amostras cujos componentes majoritários sejam lipídeos. Entretanto, alguns ensaios são de difícil adaptação para a análise de óleos vegetais, tornando os resultados de difícil interpretação e pouco informativos. É crescente o número de investigações a respeito da capacidade antioxidante de óleos vegetais, porém ainda não há consenso a respeito da melhor maneira de adaptar os ensaios disponíveis, e a quantidade de informação publicada ainda é insuficiente.

Esta revisão tem como objetivos sistematizar conhecimentos sobre os fundamentos e a aplicação de ensaios de capacidade antioxidante para a análise de óleos e avaliar criticamente o potencial que os ensaios de capacidade antioxidante apresentam como indicadores da bioatividade dos óleos e, possivelmente, da estabilidade de óleos específicos. Dessa forma, espera-se estimular a geração de conhecimentos científicos mais abrangentes quanto aos determinantes e a avaliação da qualidade dos óleos vegetais comestíveis.

\section{Métodos de análise da capacidade antioxidante total de óleos vegetais}

Os ensaios analíticos utilizados para a determinação da capacidade antioxidante são baseados em dois mecanismos de reação (Figura 2):
Transferência de Átomo de Hidrogênio (HAT Hydrogen Atom Transfer) e Transferência de um Elétron (SET - Single Electron Transfer). Para ambos os mecanismos de reação o objetivo é determinar o efeito protetor da amostra contra os radicais livres, porém eles se diferenciam quanto ao radical iniciador, à cinética da reação e às reações laterais ${ }^{6}$.

Os métodos baseados no mecanismo de HAT investigam a capacidade dos antioxidantes em bloquear a ação dos Radicais Peroxila (ROO*) através da doação de hidrogênio. Esses ensaios são compostos por um gerador sintético de radicais, responsável pela manutenção do fluxo constante de ROO*, pelos antioxidantes (da amostra ou do padrão) e por uma sonda molecular (substrato oxidável) que, quando oxidada pela espécie reativa, apresenta sinal mensurável (absorbância UV-Vis ou fluorescência). O antioxidante inibe, por competição, a oxidação do substrato pela espécie reativa de oxigênio. Consequentemente ocorrerá uma mudança no sinal medido, e a capacidade antioxidante da amostra pode ser quantificada. A presença dos ROO• no sistema como iniciadores da oxidação e a reação de competição, que é similar à peroxidação lipídica ocorrida naturalmente nos alimentos, tornam os ensaios com mecanismo de HAT representativos de um sistema alimentar em condições reais. Entretanto, ainda existem controvérsias a respeito

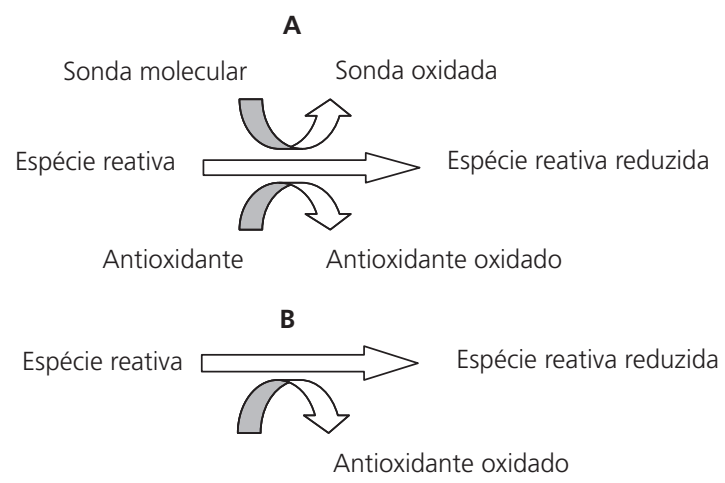

Figura 2. Esquemas dos principais mecanismos de reação dos ensaios de capacidade antioxidante total, aplicados na análise de óleos vegetais.

Nota: A: mecanismo de transferência de átomo de hidrogênio (HAT); $B$ : mecanismo de transferência de um elétron (SET). 
dessa representatividade, pois nesses ensaios a concentração do substrato oxidável (sonda molecular) é frequentemente menor do que a do antioxidante. Essa condição é contrastante com as condições reais da peroxidação lipídica em alimentos, onde a concentração do antioxidante é muito menor do que a do substrato oxidável ${ }^{5,6}$.

Os métodos baseados no mecanismo de SET envolvem apenas dois componentes: os antioxidantes e o agente oxidante, que também será a sonda molecular, responsável pelo sinal mensurável da reação (absorbância UV-Vis). A sonda oxidante abstrai um elétron do antioxidante, causando uma mudança na sua própria absorbância, permitindo o acompanhamento da reação e a determinação da capacidade antioxidante da amostra. Dessa forma, os ensaios com mecanismo de SET detectam a capacidade da amostra em reduzir o oxidante, que não precisa ser estritamente um radical livre, ao contrário dos ensaios com mecanismo de HAT. Compostos carbonílicos e metais também participam como agentes oxidantes nesse tipo de ensaio. Os ensaios de SET apresentam mecanismos não competitivos e não se utilizam de espécies reativas de oxigênio e, por isso, são considerados menos representativos das condições reais em um alimento, quando comparados aos ensaios com mecanismo de HAT $^{5,6}$.

Os mecanismos de SET e HAT, na maioria das vezes, ocorrem simultaneamente nos alimentos, e seu equilíbrio é determinado principalmente pelas propriedades químicas dos antioxidantes e pelas características físico-químicas do alimento. Portanto, para que a determinação da capacidade antioxidante seja mais completa e representativa, recomenda-se o uso de mais de um ensaio, de modo a contemplar ambos os mecanismos de reação.

Muitos ensaios já foram desenvolvidos para determinar a capacidade antioxidante dos alimentos de composição complexa, como reportado em revisões recentes da literatura ${ }^{5,6,8}$. Entretanto, ainda não existem ensaios recomendados oficialmente, embora Prior et al. ${ }^{6}$ tenham sugerido três ensaios como candidatos potenciais para padronização: ORAC (Oxygen Radical Absorbance Capacity), baseado no mecanismo de HAT; TEAC (Trolox Equivalent Antioxidant Capacity) e o ensaio de Folin-Ciocalteu, ambos baseados no mecanismo de SET. A falta de padronização dos ensaios faz com que existam diferenças fundamentais nos protocolos analíticos, como o uso de diferentes solventes e a adoção de diferentes pontos-finais da reação e maneiras de expressar os resultados. Essas importantes variações nos protocolos limitam as possibilidades de comparações entre amostras de alimentos de diferentes estudos, uma vez que afetam os valores da capacidade antioxidante ${ }^{9,10}$.

As propriedades físico-químicas da fração hidrofílica e da fração lipofílica dos óleos vegetais são extremamente diferentes. Quanto à sua composição química, a fração hidrofílica apresenta os compostos fenólicos, enquanto a fração lipofílica apresenta os tocóis, os esteróis, os carotenoides, as clorofilas e os acil-gliceróis. Devido aos diferentes métodos de extração da fração hidrofílica, que em geral se utilizam de metanol ou acetona, no presente trabalho a fração hidrofílica será chamada de fração polar, e a fração lipofílica, de fração apolar. Sugere-se que, para a obtenção de resultados representativos da capacidade antioxidante de óleos, a fração apolar deve ser separada da polar, devendo ser determinada separadamente a capacidade antioxidante de cada uma delas. Dessa forma, o somatório da capacidade antioxidante das frações deve representar a capacidade antioxidante integral do óleo ${ }^{4}$.

No entanto, a atividade antioxidante dos componentes dos óleos pode ser afetada pelo sinergismo entre os compostos antioxidantes e pela complexa afinidade dos compostos com as interfaces ar-óleo, ar-água e/ou óleo-água no meio ${ }^{11-13}$. A localização dos antioxidantes em interfaces causa um fenômeno conhecido como paradoxo polar, no qual os antioxidantes polares são mais efetivos em meios apolares e vice-versa ${ }^{13}$. Consistentemente com essas complexas interações moleculares, Espín et al. ${ }^{14}$ observaram maiores 
valores de capacidade antioxidante em óleos vegetais analisados sem separação de frações, quando comparados aos somatórios das frações polar e apolar. Esses resultados sugerem mecanismos de ação distintos para os compostos antioxidantes nas diferentes frações isoladas. Portanto, é recomendável determinar a capacidade antioxidante integral dos óleos através das duas abordagens, na amostra integral e pelo somatório da capacidade antioxidante das frações polar e apolar. Essa recomendação tem sido atendida em estudos recentes ${ }^{15}$.

Recentemente, diferentes métodos têm sido utilizados para a determinação da capacidade antioxidante em óleos vegetais, como os ensaios da TEAC ${ }^{16}$, do $\mathrm{DPPH}^{*}$ (radical 2,2- difenil-1picrilhidrazilo) ${ }^{14,15}$, do FRAP (Ferric Reducing Antioxidant Power $)^{1,17}$ e da ORAC ${ }^{1,18}$. Embora Prior et al. ${ }^{6}$ tenham sugerido que apenas os ensaios de TEAC e ORAC são passíveis de adaptação para os compostos lipofílicos, houve adaptações de protocolos para outros ensaios ${ }^{14,19}$. No Quadro 1, destacam-se algumas das principais características e diferenças entre os ensaios mais utilizados para a determinação da capacidade antioxidante de óleos vegetais.
O ensaio do DPPH é o mais amplamente utilizado para a determinação da capacidade antioxidante em diferentes óleos vegetais ${ }^{14,15,20}$. Esse ensaio envolve o mecanismo de SET e marginalmente o de HAT, e baseia-se na determinação da capacidade dos antioxidantes (da amostra ou do padrão) em reduzir o radical DPPH ${ }^{\bullet}$. A capacidade redutora da amostra é determinada através da redução da absorbância (515-528nm) do radical por 30 minutos ou até cessar a queda na absorbância ${ }^{6}$. Geralmente, os resultados são apresentados como $\mathrm{EC}_{50^{\prime}}$ que expressa a concentração de amostra antioxidante ou padrão, necessária para reduzir em $50 \%$ a concentração inicial do $\mathrm{DPPH}^{\circ}$. Originalmente, o ensaio utiliza metanol como solvente para o $\mathrm{DPPH}^{\circ}$ e para as amostras ${ }^{5}$. No entanto, como o metanol não dissolve óleos comestíveis, são necessárias adaptações para os compostos lipofílicos dos óleos vegetais, por meio da utilização de solventes apropriados para amostras lipídicas.

Espin et al. ${ }^{14}$ testaram o efeito da dissolução do DPPH e da fração apolar dos óleos vegetais com diferentes solventes orgânicos sobre a capacidade antioxidante. Os melhores resultados foram obtidos com o acetato de etila, sendo esse protocolo seguido em alguns estudos poste-

Quadro 1. Características selecionadas e principais diferenças entre os ensaios mais utilizados para a determinação in vitro da capacidade antioxidante total (CAT) de óleos vegetais.

\begin{tabular}{|c|c|c|c|c|c|}
\hline Ensaio $^{a}$ & $\begin{array}{l}\text { Mecanismo } \\
\text { da reação }\end{array}$ & $\begin{array}{l}\text { Acompanhamento } \\
\text { da reação }\end{array}$ & $\begin{array}{c}\text { Princípio do cálculo } \\
\text { da CAT }\end{array}$ & $\begin{array}{l}\text { CAT lipofílica } \\
\text { e hidrofilica }\end{array}$ & $\begin{array}{l}\text { Referências de aplicação } \\
\text { em óleos vegetais }\end{array}$ \\
\hline DPPH & HAT e SET & Espectrofotometria 515-528nm & $\mathrm{EC}_{50}$ & Não & $2,14,15,20$ e 21 \\
\hline TEAC & HAT e SET & Espectrofotometria 734nm & $\begin{array}{l}\text { Abs }_{\text {Final }}-A b s_{\text {Inicial }} \\
\text { ou } \\
\text { AUC de Abs vs.t }\end{array}$ & Sim & 16 e 23 \\
\hline FRAP & SET & Espectrofotometria $595 \mathrm{~nm}$ & $A b S_{\text {Final }}-A b s_{\text {Inicial }}$ & Não & 1,17 e 24 \\
\hline ORAC & HAT & $\begin{array}{l}\text { Fluorimetria excitação } 485 \mathrm{~nm} \\
\text { emissão } 525 \mathrm{~nm}\end{array}$ & AUC de Abs vs. $t$ & Sim & $1,10,18$ e 25 \\
\hline
\end{tabular}

a DPPH: DPPH assay (ensaio do radical 2,2- difenil-1-picrilhidrazilo); TEAC: trolox equivalent antioxidant capacity (capacidade antioxidante em equivalentes de trolox), também conhecido por ensaio ABTS, em função do radical estável ABTS*+ usado no ensaio; FRAP: ferric reducing antioxidant power (poder antioxidante por redução do íon férrico); ORAC: oxygen radical absorbance capacity (capacidade de absorção de radicais de oxigênio).

b HAT: transferência de átomo de hidrogênio. (hydrogen atom transfer); SET: transferência de um elétron (single electron transfer).

${ }^{\mathrm{C}} \mathrm{EC} \mathrm{F}_{50}$, quantidade de amostra necessária para reduzir à metade a absorbância inicial do radical DPPH; Abs, absorbância; AUC de Abs vs. t (min), área abaixo da curva de absorbância contra o tempo do ensaio em minutos. 
riores $^{15,20}$. Outros solventes têm sido utilizados, tais como tolueno ${ }^{2}$ e isooctano ${ }^{21}$, porém são menos frequentes na literatura. Nos estudos que utilizaram o ensaio do DPPH ${ }^{\bullet}$, observa-se que, além de diferentes solventes, foram empregadas diferentes maneiras de expressar os resultados, tornando-os não comparáveis diretamente 2,14,15,20,21. Pelo ensaio do DPPH, em geral os óleos de soja e de milho apresentam os maiores valores de capacidade antioxidante integral e para a fração apolar, enquanto o azeite de oliva extra-virgem apresenta os maiores valores de capacidade antioxidante para a fração polar.

Assim como o ensaio do radical DPPH, o ensaio da TEAC baseia-se nos mecanismos de SET e HAT. O ensaio da TEAC estima a capacidade do antioxidante em eliminar o radical cromóforo ABTS $^{\bullet+}$ (2,2' -azino-bis-(3-etil-benzotiazolina)-6sulfônico), que tem sua absorbância reduzida à medida que reage com os antioxidantes. Observam-se picos de absorbância do radical ABTS•+ nos comprimentos de onda de 414, 645, 734 e $815 \mathrm{~nm}$. Entretanto, $734 \mathrm{~nm}$ é o comprimento de onda de escolha, pois minimiza a influência da turbidez e de interferentes da amostra ${ }^{8}$. O trolox (6-hidroxi-2, 5,7,8-tetrametilcromano-2-ácido carboxílico, análogo hidrossolúvel da vita-mina E) é o antioxidante usado como padrão nesse ensaio, e a reatividade das amostras é expressa como equivalentes molares desse padrão. O grau de eliminação do $A B T S$ •+ é determinado em função da concentração dos antioxidantes (padrão ou amostras) em tempos de reação fixos pré-determinados ou em ensaio cinético onde se mede a contribuição total da atividade antioxidante através do cálculo da área abaixo da curva de Absorbância vs. tempo 22 .

O ensaio da TEAC tem sido utilizado na determinação da capacidade antioxidante de diferentes óleos vegetais ${ }^{16,23}$. Segundo Pellegrini et $a / .{ }^{16}$, o uso do solvente $n$-hexano permitiu meIhor solubilização das amostras de óleo e, consequentemente, maior ação antioxidante de seus componentes. Nessa investigação, o hexano foi compatível apenas com o ensaio da TEAC, pois não foi possível dissolver em hexano os reagentes usados nos ensaios de FRAP e TRAP (Total Radical-trapping Antioxidant Potential), que também foram investigados. Dessa forma, pode-se sugerir que a TEAC possibilita uma determinação mais completa da capacidade antioxidante de óleos, pois é compatível com o uso de solvente suficientemente apolar para dissolver amostras lipídicas. Resultados do ensaio da TEAC indicam que amostras dos óleos de soja e milho apresentam valores relativamente elevados de capacidade antioxidante, enquanto o azeite de oliva refinado apresenta valores relativamente baixos. Obteve-se ranqueamento similar dos valores de capacidade antioxidante desses óleos, quando analisados pelo ensaio do DPPH ${ }^{\bullet 16,23}$. Dessa forma, pode-se sugerir que o ensaio do $\mathrm{DPPH}^{\bullet}$ pode ser aplicado para ranquear as amostras de óleo quanto à capacidade antioxidante, embora não apresente resultados quantitativos representativos da capacidade antioxidante de óleos.

O ensaio do FRAP é totalmente baseado no mecanismo de SET e estima a capacidade dos antioxidantes em reduzir o complexo de Ferro Férrico Tripiridiltriazina ( $\left.\mathrm{Fe}^{+3}-\mathrm{TPTZ}\right)$ ao complexo de Ferro Ferroso Tripiridiltriazina $\left(\mathrm{Fe}^{+2}\right.$ - TPTZ) em pH 3,6. No ensaio do FRAP, o complexo Fe+2-TPTZ, formado na presença de antioxidantes, apresenta coloração azul e a absorbância da solução é medida em 595nm, permitindo o monitoramento da atividade redutora da amostra. Recentemente, os resultados desse ensaio têm sido apresentados como equivalentes de trolox ${ }^{10}$. Devido aos potenciais redox comparáveis do Fe+3-TPTZ $(0,70 \mathrm{~V})$ e do $\operatorname{ABTS}^{\bullet+}(0,68 \mathrm{~V})$, os compostos antioxidantes que reagem no ensaio do FRAP tendem a reagir de forma similar no ensaio da TEAC, gerando resultados que se correlacionam positivamente ${ }^{19}$.

O ensaio do FRAP tem sido utilizado principalmente para determinação da capacidade antioxidante na fração polar de óleos vegetais ricos em compostos fenólicos, como azeite de oliva e óleo de canola ${ }^{1,24}$, pois o reagente do ensaio do FRAP é incompatível com os solventes orgânicos 
utilizados para dissolver óleos ou sua fração apolar ${ }^{6}$. Recentemente, Jimenez-Alverez et al. ${ }^{19}$ reportaram o uso de $\beta$-ciclodextrina aleatoriamente metilada para dissolver adequadamente a fração apolar de orégano e permitir a reação desse extrato com o reagente do FRAP. Entretanto, não foi possível localizar artigos publicados que reportassem a aplicação dessa abordagem analítica para a determinação da capacidade antioxidante de óleos vegetais.

O ensaio da ORAC baseia-se no mecanismo de HAT, sendo o método mais indicado para avaliar a capacidade protetora de amostras de alimentos contra os ROO*. A sonda molecular (fluoresceína) usada nesse ensaio tem sua fluorescência reduzida como consequência da oxidação promovida por radicais livres. A capacidade dos antioxidantes em retardarem a redução da fluorescência da sonda molecular é monitorada fluorometricamente (ex 485nm/ em 525nm) por 35 minutos a $37^{\circ} \mathrm{C}$. A quantificação dos resultados é realizada através do cálculo da área abaixo da curva e expressa como equivalentes de trolox, que é usado como padrão ${ }^{5-7}$. Segundo Prior et al. ${ }^{6}$ resultados mais reprodutíveis tem sido obtidos com a utilização de leitores de microplacas com injetor automático e controle de temperatura, capazes de ler a fluorescência em ensaio cinético.

Os ensaios da ORAC, assim como o ensaio do FRAP, têm sido utilizados para a determinação da capacidade antioxidante da fração polar de óleos vegetais com concentração relativamente elevada de compostos fenólicos ${ }^{1,7,25}$. Contudo, esse ensaio pode ser adaptado para estimar a capacidade antioxidante de ambas as frações dos óleos vegetais, utilizando o mesmo gerador de radicais e sonda molecular. Huang et al. ${ }^{26}$ introduziram e validaram o uso da $\beta$-ciclodextrina aleatoriamente metilada como meio para a dispersão dos antioxidantes lipofílicos na solução aquosa do ensaio da ORAC. No entanto, apenas recentemente, Miraliakbari et al. ${ }^{18}$ utilizaram a $\beta$-ciclodextrina aleatoriamente metilada no ensaio da ORAC para determinar a capacidade antioxidante de óleos de nozes e castanhas. A $\beta$-ciclodextrina metilada parece ser um bom candidato para tornar os óleos vegetais compatíveis com os ensaios que utilizam solventes polares.

É importante notar que a polaridade dos solventes influencia ambos os mecanismos de atividade antioxidante dos ensaios, pois afetam a doação de átomos de hidrogênio e a transferência de elétrons ${ }^{6,10}$. Pérez-Jiménez \& Saura-Calixto ${ }^{10}$ avaliaram a influência da polaridade do solvente sobre a capacidade antioxidante, determinada pelos ensaios de DPPH ${ }^{\circ}$, FRAP, ORAC e TEAC, em sistemas-modelo de antioxidantes. Verificou-se clara influência do solvente nos quatro ensaios. Os ensaios da ORAC e da TEAC foram os mais afetados pela polaridade do solvente, porém distintamente. O ensaio da ORAC apresentou maior capacidade antioxidante quando solventes mais apolares foram utilizados, enquanto o ensaio da TEAC apresentou maior capacidade antioxidante quando solventes mais polares foram utilizados.

A alta capacidade de formação de ligações de hidrogênio dos solventes polares pode alterar drasticamente a doação de hidrogênio dos antioxidantes, reduzindo sua capacidade antioxidante ${ }^{10}$. Em óleos vegetais, nos quais os diferentes compostos podem haver interações entre os componentes e destes com o solvente. Desta forma, a influência do solvente sobre os mecanismos de HAT e/ou SET pode ser ainda maior. Entretanto, a influência da polaridade do solvente sobre a capacidade antioxidante de óleos ainda não foi investigada de forma sistemática.

Os ensaios de DPPH', FRAP, ORAC e TEAC são os mais utilizados para a determinação da capacidade antioxidante de óleos vegetais. Recomenda-se combinar ao menos dois ou, se possível, todos os ensaios para a obtenção de informações mais completas quanto à capacidade antioxidante dos óleos. Por outro lado, só se deve fazer comparações diretas da capacidade antioxidante de óleos vegetais entre diferentes estudos quando se utilizam os mesmos ensaios e solventes; caso contrário, os resultados podem variar muito entre estudos, tornando-os incomparáveis $5^{5,6,9,10}$. 


\section{Composição físico-química de óleos vegetais e sua relação com a capacidade antioxidante total}

Os óleos vegetais constituem-se predominantemente por triacilgliceróis, frequentemente ricos em ácidos graxos poli-insaturados. Também estão presentes alguns lipídeos formados durante o processamento, como mono- e diacilgliceróis e ácidos graxos livres. Além disso, os óleos vegetais contêm pequenas quantidades de esteróis, tocoferóis, tocotrienóis, compostos fenólicos, pigmentos (carotenoides e clorofilas) e metais de transição como ferro e cobre ${ }^{3}$. Dentre esses compostos, os tocóis e compostos fenólicos têm sido objeto de muitos estudos, devido a sua atividade antioxidante.

Os óleos vegetais são a principal fonte de tocóis da alimentação, sendo os tocoferóis a principal forma de tocol encontrada na maioria dos óleos. Os tocotrienóis são menos comuns, estando presentes em maiores concentrações apenas em alguns óleos, tais como os de palma e arroz. Os tocóis constituem um grupo de moléculas que apresentam atividade de vitamina E. Existem na natureza quatro formas $(\alpha, \beta, \gamma$ e $\delta)$ de tocoferóis e tocotrienóis que são potentes antioxidantes lipofílicos. $0 \alpha$ - e o $\gamma$-tocoferol são os mais encontrados na maioria dos óleos vegetais ${ }^{27}$. 0 $\alpha$-tocoferol é o mais estudado dos tocóis, devido a sua elevada atividade biológica como vitamina E; entretanto, sugere-se que outros tocóis apresentem maior capacidade de proteger os óleos vegetais contra a peroxidação lipídica ${ }^{3}$. Existem evidências de que a capacidade antioxidante dos óleos vegetais pode ser influenciada pelo teor de tocóis totais, bem como pela concentração de alguns tocoferóis individuais como $\gamma$ - e $\delta$ tocoferóis ${ }^{14-16,20}$. Por outro lado, em testes de oxidação acelerada $\left(175^{\circ} \mathrm{C} / 18 \mathrm{~h}\right)$ observaram-se correlações da capacidade antioxidante dos óleos vegetais com os tocotrienóis $\alpha$ - e $\gamma$-, ou ausência de correlações com tocóis ${ }^{2,28}$. Essas controvérsias quanto ao papel dos tocóis como determinantes da capacidade antioxidante em óleos vegetais indicam a necessidade de mais estudos para esclarecer esses pontos.
Os compostos fenólicos são metabólitos secundários das plantas, que exibem uma variedade de ações biológicas, especialmente devido a suas propriedades antioxidantes ${ }^{29}$. Assim como ocorre para os tocóis, a atividade antioxidante varia sensivelmente entre os diferentes compostos fenólicos. Os fenólicos mais comumente detectados nos óleos vegetais fazem parte da classe dos ácidos fenólicos, especialmente os ácidos cafeico, vanílico, $p$-cumárico, siríngico, $p$-hidroxibenzoicos, além de oleuropeína, 3-hidroxifenil-etanol e 3,4 dihidroxifenil-etanol ${ }^{20,30}$. No entanto, em geral esses compostos são encontrados em baixas concentrações nos óleos refinados devido à sua baixa estabilidade ao processo de refino'. Uma exceção entre os óleos vegetais comestíveis comerciais é o azeite de oliva extra-virgem, que é rico em fenólicos, por não ser submetido ao processo de refino com suas temperaturas caracteristicamente elevadas. O azeite de oliva extra-virgem apresenta no mínimo 30 compostos fenólicos conhecidos que apresentam atividade antioxidante 24,31 . Existem evidências de que esses compostos apresentem uma maior contribuição para a estabilidade e para a capacidade antioxidante do azeite de oliva extra-virgem do que os tocoferóis nele presentes ${ }^{32}$.

A capacidade antioxidante do azeite de oliva extra-virgem apresenta correlação com o teor de fenólicos totais e individuais, especialmente com o 3,4 dihidroxifenil-etanol (hidroxitirosol) $)^{10,31,32}$. Após processo de refino, o azeite de oliva apresentou redução de $50 \%$ na capacidade antioxidante, que apresentou associação com a redução dos compostos fenólicos totais, mas não com a redução de $\alpha$-tocoferol ${ }^{23}$. Portanto, sugere-se que os compostos fenólicos sejam os principais determinantes da capacidade antioxidante do azeite de oliva. É possível que outros óleos vegetais prensados a frio apresentem teores igualmente elevados de compostos fenólicos, os quais podem apresentar importante papel como determinantes da capacidade antioxidante.

Possivelmente outros componentes dos óleos vegetais com atividade antioxidante, tais como esteróis, carotenoides e clorofilas contri- 
buem para a capacidade antioxidante total ${ }^{33}$. No entanto, assim como os compostos fenólicos, os carotenoides, as clorofilas e os esteróis são parcial ou completamente removidos ou isomerizados durante o processo de refino, apresentando-se em maiores concentrações nos óleos não refinados, como o azeite de oliva extra-virgem e o óleo de palma ${ }^{3}$. Logo, é razoável supor que esses compostos podem contribuir para a capacidade antioxidante de óleos não refinados, mas provavelmente não influenciam a capacidade antioxidante dos óleos refinados, mais consumidos. Dabbou et al..$^{33}$ observaram que os fatores que apresentaram correlação mais forte com a capacidade antioxidante, avaliada pelo ensaio da TEAC, em azeites de oliva foram os teores de carotenoides $(r=0,86 ; p=0,01)$ e de clorofilas $(r=0,76$; $p=0,01$ ), seguidos pelo teor de fenólicos totais $(r=0,64 ; p=0,05)$. Entretanto, embora se observem correlações significativas entre as variáveis, são necessárias mais investigações para confirmar o papel desses pigmentos como determinantes da capacidade antioxidante de óleos vegetais. Além disso, é possível que os carotenoides e as clorofilas apresentem ação pró-oxidante, especialmente quando a concentração de oxigênio no meio é elevada, pois a energia luminosa absorvida por esses pigmentos pode ser transferida para o oxigênio tripleto, transformando-o em oxigênio singleto de maior energia, que é um agente oxidante mais reativo.

\section{Capacidade antioxidante total e estabilidade dos óleos vegetais}

A estabilidade oxidativa é um importante determinante da qualidade dos óleos vegetais. A oxidação dos óleos é fortemente influenciada por sua composição quanto aos ácidos graxos e antioxidantes. A peroxidação lipídica envolve complexas reações radicalares autopropagantes, resultantes das interações químicas entre os ácidos graxos insaturados e espécies reativas de oxigênio. As consequências da peroxidação lipídica, tais como as perdas de ácidos graxos essenciais (lino- leico e $\alpha$-linolênico) e antioxidantes naturais, a modificação do flavor original e a produção de diversos compostos, com potenciais efeitos adversos à saúde humana, têm implicância direta no valor nutricional e comercial, assim como na segurança dos óleos vegetais ${ }^{34}$.

A degradação oxidativa dos óleos pode iniciar-se espontaneamente e pode ser acelerada por pró-oxidantes, como metais de transição, exposição à luz UV ou visível na presença de fotossensibilizador, elevadas temperaturas ou concentrações de oxigênio. A oxidação espontânea

Iniciação

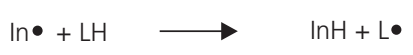

Propagação

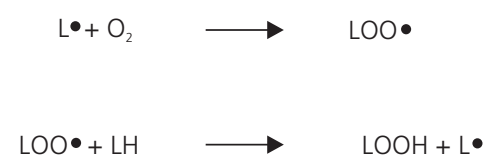

Terminação

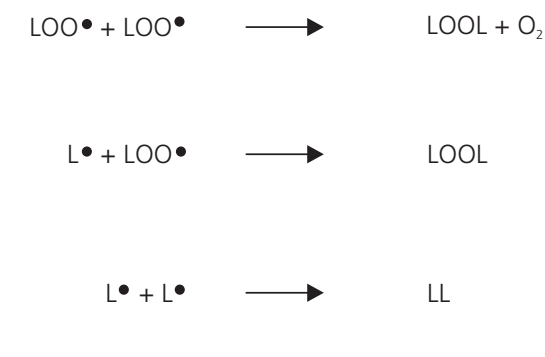

Inibição

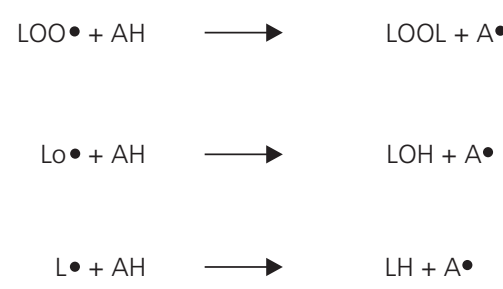

Figura 3. Sistema esquemático das principais reações da oxidação de óleos vegetais, na via de auto-oxidação.

Nota:In`: radical iniciador; LH: substrato lipídico (normalmente insaturado); L`: radical alquila; LOO•: radical peroxila; $\mathrm{LOOH}$ hidroperóxido (produto primário da lipoperoxidação); LOOL: produto estável, não-radical (produto terciário da lipoperoxidação); $\mathrm{AH}$ : antioxidante; $\mathrm{A}^{\bullet}$ : radical do antioxidante. 
dos lipídeos, chamada de auto-oxidação, é a principal via de degradação dos óleos fotoprotegidos e em temperatura ambiente. A auto-oxidação divide-se em três principais etapas: iniciação, propagação e terminação, que podem ser inibidas ou retardadas pela ação dos antioxidantes presentes nos óleos vegetais (Figura 3) 3,35-37.

Os tocóis apresentam importante papel na proteção dos óleos vegetais contra oxidação, tendo em vista que são seus principais antioxidantes lipofílicos naturais ${ }^{27}$. Os tocóis são considerados antioxidantes primários, pois reagem rapidamente com os radicais livres e, assim, inibem por competição a oxidação dos ácidos graxos insaturados. Desta forma, os tocóis retardam especialmente a etapa de propagação ${ }^{36,37}$. A atividade antioxidante dos quatro tocoferóis apresenta a seguinte ordem de eficácia: $\delta>\gamma=\beta>\alpha$; contudo essa ordem pode ser alterada por diversos fatores, tais como temperatura, disponibilidade de oxigênio, exposição à luz, entre outros ${ }^{3}$. Além disso, sabe-se que alguns tocoferóis podem agir como pró-oxidantes ${ }^{35}$.

Os compostos fenólicos são os principais responsáveis pela alta estabilidade oxidativa do azeite de oliva virgem e, assim como os tocoferóis, agem sobre a etapa de propagação. Além disso, os fenólicos podem agir como quelantes de metais de transição, inibindo a decomposição dos hidroperóxidos catalisada por metais e, possivelmente, a formação de espécies reativas de oxigênio através da reação de Fenton ${ }^{38}$. Aparício et al. ${ }^{39}$. verificaram que os fenólicos do azeite de oliva virgem contribuíram com $50 \%$ da estabilidade oxidativa do óleo, durante teste de oxidação acelerada a $100^{\circ} \mathrm{C}$ e oxigenação forçada. Além disso, fenólicos específicos do azeite de oliva, como o hidroxitirosol, parecem inibir especificamente a formação de produtos primários da oxidação ${ }^{38}$. Igualmente, a estabilidade oxidativa do azeite de oliva parece ser influenciada pela interação entre os compostos fenólicos e o $\alpha$-tocoferol, sugerindo que os compostos fenólicos são capazes de regenerar o $\alpha$-tocoferol, que continuará agindo como antioxidante ${ }^{40}$. Entretanto, essa hipótese ainda não foi confirmada diretamente.
Os pigmentos naturais carotenoides e clorofilas, além de conferirem a cor característica a tipos específicos de óleos não refinados, particularmente ao azeite de oliva extra-virgem e ao óleo de palma, influenciam na estabilidade oxidativa dos óleos. Os carotenoides, em especial o $\beta$-caroteno, podem inibir ou retardar a iniciação ou a propagação da oxidação lipídica nos óleos através da inativação de oxigênio singleto e dos radicais peroxila $\left(\mathrm{ROO}^{\circ}\right)$, respectivamente. Além disso, os carotenoides são efetivos em inibir a ação de fotossensibilizadores, como as clorofilas, que podem apresentar ação pró-oxidante na foto-oxidação de óleos vegetais. Conforme citado por Choe \& $\mathrm{Min}^{34}$, o $\beta$-caroteno foi capaz de reduzir a oxidação de óleo de soja exposto à luz, mesmo em presença de clorofilas. Ressalta-se que, embora as clorofilas apresentem ação pró-oxidante nos óleos vegetais expostos à luz, esses compostos podem agir como antioxidantes primários quando os óleos se encontram protegidos da luz ${ }^{34}$.

Apesar do extenso conhecimento a respeito do papel da peroxidação lipídica como principal via química de degradação oxidativa dos óleos, são escassos os estudos que abordaram a ação integrada dos compostos antioxidantes presentes nos óleos vegetais, através dos ensaios de capacidade antioxidante, e sua relação com a estabilidade oxidativa de óleos específicos.

A fim de estudar essas relações físico-químicas, Ninfali et al. ${ }^{25}$ e Arranz et al. ${ }^{41}$ investigaram a associação entre a capacidade antioxidante e a estabilidade oxidativa, avaliada em ensaio de oxidação forçada no equipamento Rancimat ${ }^{\circledR}$, em óleos de nozes e azeite de oliva, respectivamente. Em ambos os trabalhos observaram-se correlações positivas: $r^{2}=0,83$ e $p=0,03$, para o azeite de oliva e ensaio do $\mathrm{DPPH}^{\circ 41} ; r=0,42$ e $p<0,02$, para os óleos de nozes e ensaio da ORAC ${ }^{25}$. É precoce afirmar que os resultados de capacidade antioxidante sejam capazes de estimar a estabilidade oxidativa dos óleos vegetais. Entretanto, as correlações observadas da capacidade antioxidante com a estabilidade oxidativa avaliada no equipamento Rancimat, que é considerado um méto- 
do oficial para avaliação da estabilidade oxidativa dos óleos, indicam uso potencial da capacidade antioxidante como indicador da qualidade integral e da estabilidade dos óleos vegetais.

São necessários mais estudos utilizando outros óleos, outros ensaios de capacidade antioxidante e de oxidação acelerada, para que as associações entre a capacidade antioxidante e a estabilidade oxidativa dos óleos seja determinada. Caso seja confirmada a representatividade da capacidade antioxidante como indicador da estabilidade oxidativa de óleos vegetais, ensaios de capacidade antioxidante poderão ser aplicados como métodos de controle de qualidade, especialmente os ensaios de TEAC e ORAC, recomendados para padronização das análises. Essas hipóteses merecem confirmação direta, através de estudos desenhados com essa finalidade específica.

\section{Capacidade antioxidante total e bioatividade dos óleos vegetais}

Diversos radicais livres são constantemente formados pelo organismo humano através do metabolismo energético e de sistemas de defesa imune. Essas substâncias contribuem positivamente para o funcionamento normal do organismo humano. Entretanto, a concentração dessas espécies reativas pode superar a capacidade do organismo de eliminá-las, devido à maior produção intracelular e/ou à ineficiência dos mecanismos de proteção antioxidante. O desequilíbrio em favor da formação dos radicais, denominado estresse oxidativo, quando mantido por período de tempo relativamente prolongado, pode promover danos oxidativos que culminam com o desenvolvimento de doenças crônicas ${ }^{42}$.

A oxidação de lipídeos, proteínas e ácidos nucleicos, através da ação de espécies reativas, é associada com o desenvolvimento de diversos tipos de câncer, doenças cardiovasculares e neurodegenerativas. As células, tecidos e fluídos corporais apresentam importantes sistemas endógenos de defesa, capazes de eliminar diversas espécies reativas, minimizando os danos oxidativos causados pelos radicais livres. Esses sistemas de defesa endógena constituem-se por, pelo menos, quatro classes de agentes antioxidantes: 1) as enzimas superóxido dismutases, catalases, glutationa peroxidase e redutase; 2) as macromoléculas albumina, ceruloplasmina, transferrina, ferritina e outras; 3) as micromoléculas, ácido úrico, glutationa e outras; 4) os hormônios estrogênio e melatonina. Além dos mecanismos endógenos de proteção contra o dano oxidativo, antioxidantes de origem exógena, amplamente distribuídos nos alimentos de origem vegetal, também apresentam papel determinante sobre o risco de danos oxidativos e suas consequências deletérias ${ }^{6,42}$.

Estudos epidemiológicos têm observado uma forte associação entre a redução do risco de desenvolvimento de doenças cardiovasculares e alguns tipos de câncer com o consumo de óleos vegetais, especialmente o azeite de oliva extra-virgem. Os compostos responsáveis por esses efeitos ainda não são totalmente conhecidos, porém sugere-se que os antioxidantes naturais estejam entre os principais responsáveis. Por outro lado, os mecanismos pelos quais os antioxidantes dos alimentos contribuem para o sistema antioxidante endógeno também não estão completamente elucidados ${ }^{43}$.

Os compostos fenólicos e a vitamina E suprimem a oxidação e protegem biomoléculas contra danos oxidativos ${ }^{42}$. $0 \alpha$-tocoferol é o mais estudado dos tocoferóis, devido a sua elevada concentração no plasma humano, células e tecidos corporais. Entretanto, possivelmente outros tocóis além do $\alpha$-tocoferol apresentam bioatividade $^{27}$. Além disso, existem fortes evidências de que os fenólicos do azeite de oliva extra-virgem apresentam maior efeito protetor contra a oxidação de lipídeos e DNA do que o $\alpha$-tocofero ${ }^{44}$. $\mathrm{O}$ hidroxitirosol é um potente antioxidante presente no azeite de oliva virgem e, recentemente, descobriu-se que seus metabólitos também apresentam atividade antioxidante in vitro ${ }^{38}$. Boa parte do hidroxitirosol se perde durante o processo de 
refino dos óleos ${ }^{20}$, de modo que esse composto está ausente nos óleos refinados. Portanto, pode-se atribuir à ação desse fenólico ao menos parte do efeito antioxidante in vivo e dos benefícios do consumo de azeite de oliva extra-virgem.

A capacidade antioxidante tem sido utilizada como indicador da bioatividade dos óleos vegetais no organismo humano. Através dos valores de capacidade antioxidante in vitro é possível ranquear os óleos vegetais quanto a seu potencial efeito benéfico no organismo humano. Entretanto, é razoável supor que a ação dos principais antioxidantes dietéticos de importância biológica in vivo dependam de fatores, como o nível de estresse oxidativo ao qual o organismo é exposto, a composição e as quantidades de antioxidantes e pró-oxidantes habitualmente ingeridos, assim como da biodisponibilidade e do metabolismo dos compostos antioxidantes no organismo humano ${ }^{45}$.

Recentemente, Pellegrini et al. ${ }^{43}$ desenvolveram e validaram um questionário de frequência alimentar para estimar a capacidade antioxidante da dieta habitual, incluindo o consumo de óleos vegetais. A capacidade antioxidante da dieta habitual foi comparada com a capacidade antioxidante plasmática dos mesmos indivíduos, porém não houve correlação entre essas duas variáveis. Provavelmente, a capacidade antioxidante do plasma é dependente de fatores que não foram considerados na investigação, tais como a biodisponibilidade dos antioxidantes dos alimentos, níveis de ingestão de pró-oxidantes e de substratos oxidáveis, entre outros fatores exógenos, assim como dos mecanismos endógenos de proteção ${ }^{46}$. No que diz respeito à biodisponibilidade dos antioxidantes dos alimentos, sugere-se que dependa de fatores exógenos e endógenos, tais como a complexidade da matriz alimentar, a estrutura e a quantidade de compostos antioxidantes ingeridos em uma mesma refeição, a taxa de esvaziamento gástrico, o trânsito intestinal, a presença de proteínas ligantes de antioxidantes no plasma e nos tecidos, entre outros fatores ${ }^{46}$.
Saura-Calixto \& Goñi ${ }^{47}$ também investigaram a associação entre a capacidade antioxidante da dieta habitual e a capacidade antioxidante do plasma e observaram que alimentos que apresentam elevada capacidade antioxidante in vitro, como o azeite de oliva extra-virgem, contribuíram pouco para a capacidade antioxidante da dieta habitual $(<2 \%)$ quando comparados a outros alimentos com menor capacidade antioxidante in vitro, mas com maior consumo habitual. É possível que óleos vegetais que apresentam menor capacidade antioxidante do que o azeite de oliva extra-virgem e que são mais consumidos pela população apresentem maior contribuição para a capacidade antioxidante da dieta habitual. Entretanto, essa hipótese ainda não foi investigada e merece confirmação.

Portanto, o estudo da capacidade antioxidante de óleos vegetais nos seres humanos in vivo deve considerar não só a capacidade antioxidante dos alimentos in vitro, mas também diversos outros fatores, a fim de obterem-se respostas mais abrangentes e exatas. Alguns desses fatores incluem a absorção, o transporte, o metabolismo e a excreção dos componentes antioxidantes e seus metabólitos ${ }^{45}$. Além disso, sempre que possível deve-se considerar a dieta habitual (quali- e quantitativamente) quanto às fontes alimentares de anti- e pró-oxidantes. Deve-se também ressaltar que a maioria dos antioxidantes, como os tocoferóis e os compostos fenólicos, podem apresentar outras funções biológicas como propriedades anti-inflamatórias, neuroprotetoras e quimiopreventivas que devem ser consideradas juntamente com sua capacidade antioxidante para uma apreciação mais completa a respeito da bioatividade dos óleos vegetais ${ }^{28,38,45}$.

\section{CONSIDERAÇÕ ES FINAIS}

A investigação da capacidade antioxidante de óleos comestíveis pode contribuir para o entendimento de dois dos principais aspectos de relevância para a ciência de alimentos e a nutrição: 1) sua estabilidade oxidativa e determinantes 
químicos; 2) sua bioatividade no organismo humano. A maior parte dos óleos vegetais apresenta maior contribuição dos antioxidantes lipofílicos para sua capacidade antioxidante; dessa forma, destaca-se a necessidade do desenvolvimento ou adaptação e uso de metodologias analíticas apropriadas para compostos lipofílicos e/ou para a fração apolar dos alimentos. Além disso, uma vez que não existe um único ensaio capaz de determinar, de forma completa ou compreensiva, a capacidade antioxidante dos alimentos, a determinação da capacidade antioxidante dos óleos deve ser realizada através de pelo menos dois ensaios, com mecanismos de reação diferenciados. A capacidade antioxidante representa parte da bioatividade dos componentes dos óleos vegetais e pode apresentar associação com a estabilidade oxidativa de óleos vegetais específicos. Dessa forma, os ensaios de capacidade antioxidante apresentam potencial de aplicação no controle de qualidade integral de óleos vegetais comestíveis. Neste trabalho ressaltaram-se de forma integrada e resumida os principais pontoschave para a investigação da capacidade antioxidante em óleos vegetais, assim como destacaram-se alguns dos aspectos controvertidos que necessitam de investigação, de modo a contribuir para a expansão do conhecimento a respeito da capacidade antioxidante de óleos comestíveis e sua relação com a estabilidade e a bioatividade desses alimentos.

\section{A GRADECIMENTOS}

À Coordenação de Aperfeiçoamento de Pessoal de Nível Superior (Capes), ao Conselho Nacional de Desenvolvimento Científico e Tecnológico (CNPq) e à Fundação de Amparo à Pesquisa do Estado do Rio de Janeiro (FAPERJ), pelo financiamento da pesquisa pela bolsa de Mestrado de V.N. CASTELO-BRANCO.

\section{COLABORADORES}

Ambos os autores participaram da concepção, redação e revisão do texto final do trabalho.

\section{REFERÊ NCIAS}

1. Szydłowska-Czerniak A, Karlovits G, Dianoczki C, Recseg K, SzBłyk E. Comparison of two analytical methods for assessing antioxidant capacity of rapeseed and olive oils. J Am Oil Chem Soc. 2008; 85:141-49. doi: 10.1007/s11746-007-1178-6.

2. Ramadan MF, Moersel JT. Screening of the antiradical action of vegetable oils. J Food Compost Anal. 2006; 19:838-42. doi: 10.1016/j.jfca.2006.0 2.013.

3. Chaiyasit W, Elias RJ, McClements DJ, Decker EA. Role of physical structures in bulk oils on lipid oxidation. Crit Rev Food Sci Nutr. 2007; 47:299-317. doi: 10.1080/10408390600754248.

4. Wu X, Gu L, Holden J, Haytowitz DB,.Gebhardt $\mathrm{SE}$, Beecher $\mathrm{G}$, et al. Development of a database for total antioxidant capacity in foods: a preliminary study. J Food Compost Anal. 2004; 17:407-22. doi: 10.1016/j.jfca.2004.03.001.

5. Huang D, Ou B, Prior R. The Chemistry behind antioxidant capacity assays. J Agric Food Chem. 2005; 53:1841-56. doi: 10.1021/jf030723c.

6. Prior RL, Wu X, Schaich K. Standardized methods for the determination of antioxidant capacity and phenolics in foods and dietary supplements. J Agric Food Chem. 2005; 53:4290-302. doi: 10.1021/jf05 02698.

7. Ninfali $P$, Aluigi $G$, Bacchiocca M, Magnani M. Antioxidant capacity of extra-virgin olive oils. J Am Oil Chem Soc. 78:243-7. doi: 10.1007/s11746-0 01-0252-9.

8. Magalhães LM, Segundo MA, Reis S, Lima JLFC. Methodological aspects about in vitro evaluation of antioxidant properties. Anal Chim Acta. 2008; 613:1-19. doi: 10.1016/j.aca.2008.02.047.

9. Pérez-Jiménez J, Arranz S, Tabernero M, Díaz-Rubio ME, Serrano J, Goñi I, et al. Updated methodology to determine antioxidant capacity in plant foods, oils and beverages: extraction, measurement and expression of results. Food Res Intern. 2008; 41: 274-85. doi: 10.1016/j.foodres.2007.12.004.

10. Pérez-Jiménez J, Saura-Calixto F. Effect of solvent and certain food constituents on different antioxidant capacity assays. Food Res Int. 2006; 39:791-800. doi: 10.1016/j.foodres.2006.02.003.

11. Sherwin ER. Antioxidants for vegetable oils. J Am Oil Chem Soc. 1976; 53:430-6. doi: 10.1007/BF026 05739.

12. Frankel EN, Huang SW, Kanner J, German JB. Interfacial phenomena in the evaluation of antioxidants: bulk oils vs emulsions. J Agric Food Chem. 1994; 42:1054-9. doi: 10.1021/jf00041 a001. 
13. Frankel EN. Antioxidants in lipid foods and their impact on food quality. Food Chem. 1996; 57:51-5. doi: 10.1016/0308-8146(96)00067-2.

14. Espín JC, Soler-Rivas C, Wichers HJ. Characterization of the total free radical scavenger capacity of vegetable oils and oil fractions using 2,2-diphenyl1-picrylhydrazyl radical. J Agric Food Chem. 2000; 48:648-56. doi: 10.1021/jf9908188.

15. Tuberoso CIG, Kowalczyk A, Sarritzu E, Cabras P. Determination of antioxidant compounds and antioxidant activity in commercial oilseeds for food use. Food Chem. 2007; 103:1494-501. doi: 10.10 16/j.foodchem.2006.08.014.

16. Pellegrini N, Serafini M, Colombi B, Del Rio D, Salvatore S, Bianchi $M$, et al. Total antioxidant capacity of plant foods, beverages and oils consumed in Italy assessed by three different in vitro assays. J Nutr. 2003; 133:2812-19.

17. SzydBłowska-Czerniak A, Dianoczki C, Recseg K, Karlovits G, SzBłyka E. Determination of antioxidant capacities of vegetable oils by ferric-ion spectrophotometric methods. Talanta. 2008; 76:899-905. doi: 10.1016/j.talanta.2008.04.055.

18. Miraliakbari $H$, Shahidi F. Antioxidant activity of minor components of tree nut oils. Food Chem. 2008; 111:421-27. doi: 10.1016/j.foodchem. 200 8.04.008

19. Jimenez-Alvarez D, Giuffrida F, Vanrobaeys F, Golay PA, Cotting C, Lardeau A, et al. High-throughput methods to assess lipophilic and hydrophilic antioxidant capacity of food extracts in vitro. J Agric Food Chem. 2008; 56:3470-77. doi: 10.1021/jf70 3723s.

20. Valavanidis A, Nisiotou C, Papageorgiou Y, Kremli I, Satravelas N, Zinieris N, et al. Comparison of the radical scavenging potential of polar and lipidic fractions of olive oil and other vegetable oils under normal conditions and after thermal treatment. J Agric Food Chem. 2004; 52:2358-65. doi: 10.10 21/jf030491h.

21. Lee JM, Chung H, Chang OS, Lee JH. Development of a method predicting the oxidative stability of edible oils using 2,2-diphenyl-1-picrylhydrazyl (DPPH). Food Chem. 2006; 103(2):662-9. doi: 10.10 16/j.foodchem.2006.07.052.

22. Re R, Pellegrini N, Proteggente A, Pannala A, Yang M, Rice-Evans C. Antioxidant activity applying an improved ABTS radical cation decolorization assay. Free Radic Biol Med. 1999; 26(9/10):1231-7. doi: 10.1016/S0891-5849(98)00315-3.

23. Sanchez CS, González AMT, García-Parrilla MC, Granados JJQ, La Serrana HLG, Martinez MCL. Different radical scavenging tests in virgin olive oil and their relation to the total phenol content. Anal
Chim Acta. 2007; 593:103-7. doi: 10.1016/j.aca.20 07.04.037.

24. Gorinstein S, Martin-Belloso O, Katrich E, Lojek A, Ciz M, Gligelmo-Miguel N, et al. Comparison of the contents of the main biochemical compounds and the antioxidant activity of some Spanish olive oils as determined by four different radical scavenging tests. J Nutr Biochem. 2003; 14:154-59. doi: 10.1016/S0955-2863(02)00278-4.

25. Ninfali P, Bacchiocca M, Biagiotti M, Servili M, Montedoro G. Validation of the oxygen radical absorbance capacity (ORAC) parameter as a new index of quality and stability of virgin olive oil. J Am Oil Chem Soc. 2002; 79:977-82. doi: 10.1007/s 11746-002-0590-7.

26. Huang D, Ou B, Hmpsch-Woodill M, Flanagan JA, Deemer EK. Development and validation of oxygen radical absorbance capacity assay for lipophilic antioxidants using randomly methylated $\beta$ cyclodextrin as the solubility enhancer. J Agric Food Chem. 2002; 50:1815-21. doi: 10.1021/jf01137 32.

27. Saldeen K, Saldeen T. Importance of tocopherols beyond $\alpha$-tocopherol: evidence from animal and human studies. Nutr Res. 2005; 25:877-89. doi: 10.1016/j.nutres.2005.09.019.

28. Rossi M, Almprese C, Ratti S. Tocopherols and tocotrienols as free radical-scavengers in refined vegetable oils and their stability during deep-fat frying. Food Chem. 2007; 102:812-17. doi: 10.10 16/j.foodchem.2006.06.016.

29. Balasundram N, Sundram K, Samman S. Phenolic compounds in plants and agri-industrial byproducts: antioxidant activity, occurrence, and potential uses. Food Chem. 2006; 99:191-203. doi: 10.1016/j.foodchem.2005.07.042.

30. Gutfinger T. Polyphenols in olive oils. J Am Oil Chem Soc. 1981; 58(11):966-68. doi: 10.1007/BF0265 9771.

31. Del Carlo M, Sacchetti G, Di Mattia C, Compagnone D, Mastrocola D, Liberatore L, et al. Contribution of the phenolic fraction to the antioxidant activity and oxidative stability of olive oil. J Agric Food Chem. 2004; 52:4072-79. doi: 10.1021/jf049806z.

32. Carrasco-Pancorbo A, Cerretani L, Bendini A, Segura-Carretero A, Del Carlo M, Gallina-Toschi, et al. Evaluation of the antioxidant capacity of individual phenolic compounds in virgin olive oil. J Agric Food Chem. 2005; 53:8918-25. doi: 10.10 21/jf0515680.

33. Dabbou S, Brahmi F, Taamali A, Issaoui M, Ouni Y, Braham $\mathrm{M}$, et al. Extra virgin olive oil components and oxidative stability from olive oils grown in 
Tunisia. J Am Oil Chem Soc. doi: 10.1007/s11746-0 10-1600-3.

34. Choe E, Min DB. Mechanisms and factors for edible oil oxidation. Compr Rev Food Sci Food Saf. 2006; 5:169-86. doi: 10.1111/j.1541-4337.2006.0000 9.x.

35. Huang SW, Frankel EN, German JB. Antioxidant activity of $\alpha$ - and $\gamma$ - tocopherols in bulk oils and in oil water emulsions. J Agric Food Chem. 1994; 42: 2108-14. doi: 10.1021/jf00046a007.

36. Huang SW, Frankel EN, German JB. Effects of individual tocopherols and tocopherol mixtures on the oxidative stability of corn oil triglycerides. J Agric Food Chem. 1995; 43:2345-50. doi: 10.1021/jf0 $0057 a 006$.

37. Mkinen M, Kamal-Eldin A, Lampi AMA, Hopia A. Effects of $\alpha$ - and $\gamma$-tocopherols on formation of hydroperoxides and two decomposition products from methyl linoleate. J Am Oil Chem Soc. 2000; 77:801-06. doi: 10.1007/s11746-000-0128-z.

38. Bendini A, Cerretani L, Carrasco-Pancorbo A, Gómez-Caravaca AM, Segura-Carretero A, et al. Phenolic molecules in virgin olive oils: a survey of their sensory properties, health effects, antioxidant activity and analytical methods: an overview of the last decade. Molecules. 2007; 12:1679-719. doi: 10.3390/12081679.

39. Aparício R, Roda L, Albi MA, Gutiérrez F. Effect of various compounds on virgin olive oil stability measured by Rancimat. J Agric Food Chem. 1999; 47,4150-5. doi: 10.1021/jf9812230.

40. Psomiadou E, Tsimidou M. Stability of virgin olive oil. 1. Autoxidation studies. J Agric Food Chem. 2002; 50:716- 21. doi: 10.1021/jf0108462.
41. Arranz S, Cert R, Pérez-Jiménez J, Cert A, SauraCalixto $F$. Comparison between free radical scavenging capacity and oxidative stability of nut oils. Food Chem. 2008; 110:985-90. doi: 10.1016/ j.foodchem.2008.03.021.

42. Halliwell, B. Antioxidants in human health and disease. Annu Rev Nutr. 1996; 16:33-50. doi: 10.11 46/annurev.nu.16.070196.000341.

43. Pellegrini N, Salvatore S, Valtuen S, Bedogni G, Porrini M, Pala V, et al. Development and validation of a food frequency questionnaire for the assessment of dietary total antioxidant capacity. J Nutr. 2007; 137:93-8.

44. Covas MI, Ruiz-Gutiérrez V, de la Torre R, Kafatos A, Lamuela-Raventós RM, Osada J, et al. Minor components of olive oil: evidence to date of health benefits in humans. Nutr Rev. 2006; 64:S20-S30. doi: 10.1111/j.1753-4887.2006.tb00260.x.

45. Castelo-Branco VN, Torres AG. Potential application of antioxidant capacity assays to assess the quality of edible vegetable oils. Lipid Technology. 2009; 21(7):152-5. doi: 10.1002/lite.200900035.

46. Holst B, Williamson $G$. Nutrients and phytochemicals: from bioavailability to bioefficacy beyond antioxidants. Curr Opin Biotechnol. 2008; 19:73-82. doi: 10.1016/j.copbio.2008.03.003.

47. Saura-Calixto F, Goni I. Antioxidant capacity of the Spanish Mediterranean diet. Food Chem. 2006; 94:442-7. doi: 10.1016/j.foodchem.2004.11.033.

Recebido em: 29/4/2009

Versão final reapresentada em: 26/8/2010 Aprovado em: 19/10/2010 
